\title{
Eliminação da transmissão da doença de Chagas pelo Triatoma infestans no Brasil: um fato histórico
}

\author{
Transmission elimination of Chagas' disease by \\ Triatoma infestans in Brazil: an historical fact
}

Senhor Editor:

0 Ministério da Saúde do Brasil recebeu no dia 9 de junho de 2006, a Certificação Internacional de Eliminação da Transmissão da Doença de Chagas pelo Triatoma infestans, conferida pela Organização Pan-Americana da Saúde ${ }^{6}$. Tornase importante enfatizar, no entanto, que tal certificação não representa 0 controle efetivo da doença no Brasil. A certificação representa somente a eliminação (interrupção momentânea) da transmissão da doença especificamente pelo triatomíneo da espécie T. infestans. Diferentemente da erradicação - que representa a interrupção definitiva da transmissão mesmo na ausência de qualquer ação de controle - a eliminação pressupõe a manutenção de alguma ação de controle e vigilância para que a interrupção se mantenha ${ }^{15}$.

Não há dúvida de que as estratégias de controle da doença de Chagas no Brasil têm obtido excelentes resultados nos últimos anos. Houve redução significativa do risco de transmissão da doença no país. Um grande impacto na prevalência da infecção, no adoecimento e, mesmo, na mortalidade tem sido observad ${ }^{17}$. A redução da prevalência da infecção em crianças de baixa idade, documentada através de inúmeros inquéritos sorológicos realizados em várias regiões do país, evidencia 0 virtual controle da transmissão vetorial e da transmissão congênita ${ }^{27}$.

A transmissão vetorial da doença de Chagas no país foi grandemente reduzida e há tecnologia para sustentar os níveis de controle alcançados. Além disso, a redução da transmissão vetorial resultou também na diminuição de gestantes e de doadores de sangue infectados, o que reduziu os riscos de transmissão transfusional e congênita. No entanto, seria ingênuo pensar que o problema do controle da doença de Chagas no Brasil está resolvido. Frente à redução da magnitude da doença, recentemente lograda, preocupa a progressiva perda de vontade política e de competência técnica para o controle da doença, além do risco de diminuição da participação popular nas estratégias de combate $^{2}$.
Embora a transmissão por Triatoma infestans tenha sido interrompida no Brasil, ainda não houve a eliminação de sua infestação domiciliar. Embora se acredite que tal eliminação seja possível em médio prazo, existem relatos da capacidade de repovoamento de $T$. infestans quando da interrupção de ações regulares de controle e vigilância ${ }^{3}$. A ausência de uma vigilância epidemiológica minimamente atuante representa risco concreto de recuperação do triatomismo domiciliar, sobretudo nos bolsões de pobreza e nas regiões politicamente menos representativas. Importa considerar, no entanto, que tais riscos são, em parte, diminuídos pelo próprio processo de adaptação dos triatomíneos à vivenda humana, que é lento e requer simplificações genéticas, biomorfológicas e de comportamento ${ }^{4}$.

Não se pode esquecer da peculiaridade que 0 Brasil possui: uma enorme diversidade de espécies de triatomíneos vetores da doença, sobretudo na região Nordeste ${ }^{3}$. É preocupante 0 risco de domiciliação de espécies ditas secundárias - como T. brasiliensis, T. pseudomaculata e T. sordida - , cujo habitat preferido é o peridomicílio. Porém, este processo de domicilação, geralmente, é lento e dependente de alta pressão triatomínica².

Além do controle da transmissão da doença por T. infestans - principal triatomíneo vetor - , outras evidências do sucesso obtido pelas medidas de controle vetorial são obtidas através dos indicadores entomológicos mais recentes. Tais indicadores evidenciam: redução considerável da infestação domiciliar por P. megistus - outro importante triatomíneo domiciliado - ; e, no caso das outras espécies - ditas secundárias, mais peridomiciliadas - , ainda que os resultados tenham sido menos expressivos, tem sido possível manter níveis de infestação e de colonização intradomiciliar incompatíveis com a transmissão, apesar de que, nesse caso, seja necessário um trabalho de vigilância de caráter contínuo, com pronta intervenção, uma vez haja evidência de constituição de colônias na habitação ${ }^{121617}$.

Do ponto de vista das estratégias de vigilância entomológica, a grande tendência para 0 controle vetorial de espécies secundárias é a vigilância passiva, ou seja, os focos de triatomíneos, residuais ou adventícios, sendo detectados pela

1. Acadêmicos de Medicina da Universidade Federal do Ceará, Fortaleza, CE.

Endereço para correspondência: Acad. Tiago Pessoa Tabosa e Silva. Rua Caio Cid 530, Edson Queiroz, $60811-150$ Fortaleza, CE.

e-mail: drtiagopessoa@yahoo.com.br

Recebido para publicação em 28/7/2006

Aceito em 8/9/2006 
própria população, devidamente capacitada, mas também motivada².

As estratégias de combate da transmissão transfusional da doença de Chagas no Brasil têm obtido excelentes resultados. Nota-se redução significativa dos riscos de transmissão transfusional da doença através das ações de controle das atividades hemoterápicas - além do controle vetorial que reduziu a prevalência de doadores infectados. Ainda, legislação específica sobre a qualidade da hemoterapia, laboratórios nacionais e regionais de referência foram implementados, objetivando-se uma boa sorologia pré-transfusional dos doadores, cuja cobertura tem aumentado - com vários estados alcançando 0 controle sorológico de mais de $90 \%$ das transfusões realizadas. A hemorrede pública pode ser considerada um ponto alto da Saúde Pública brasileira, ostentando um elevado padrão de qualidade $e^{4}$.

Em termos relativos a outros mecanismos, a transmissão congênita possui baixa importância epidemiológica ${ }^{11}$, mas ainda constitui uma via, em potencial, de manutenção da endemia chagásica no Brasil. É recomendável tornar rotineira a investigação de gestantes chagásicas no pré-natal e garantir 0 tratamento de recém-nascidos infectados ${ }^{14}$.

A compreensão exata do verdadeiro significado da certificação conferida ao Brasil, exige a reflexão acerca do contexto atual das atividades de controle da doença de Chagas no país. Em 1991, em virtude das semelhanças no comportamento epidemiológico da doença de Chagas no Cone Sul da América, os ministros de saúde dos países desta subregião criaram a Comissão Intergovernamental de Doença de Chagas, tendo a Organização Pan-americana da Saúde como Secretaria. Foi elaborado um programa sub-regional e um plano de ação comum a todos os países para a eliminação da infestação domiciliar por Triatoma infestans e a interrupção da transmissão de Trypanosoma cruzi por via transfusional ${ }^{1015}$.

Passados 15 anos, 0 avanço alcançado é inegável e 0 risco de transmissão da doença foi substancialmente reduzido, especialmente em alguns países ${ }^{5715}$. 0 Uruguai ${ }^{8}$, em 1997, e 0 Chile ${ }^{9}$, em 1999, receberam 0 certificado de interrupção da transmissão vetorial da doença de Chagas ${ }^{15}$. Diferentemente do Brasil, em tais países a transmissão vetorial ocorria somente por triatomíneos da espécie T. infestans ${ }^{5715}$.

Frente aos avanços alcançados no controle da doença de Chagas no Brasil, é fundamental que as atividades de vigilância epidemiológica sejam revistas e redimensionadas, adequando-se aos níveis de controle logrados e ao risco de que se restabeleça a transmissã $0^{16}$. Não se pode esquecer 0 exemplo da malária: considerada em extinção no Brasil, nas décadas de 60 e 70, graças à cloroquina e ao DDT, ressurgiu com toda a força nas décadas de 80 e 90, não somente pela resistência do P. falciparumà cloroquina, mas também pela desativação dos serviços de controle ${ }^{3}$.

No Brasil, preocupa sobremaneira a progressiva desativação da Fundação Nacional de Saúde, a propósito do projeto de descentralização das ações de saúde. Esta transição pode ser complicada se os municípios não conseguirem realizar as atividades de controle, principalmente se faltarem instâncias regionais de supervisão, articulação e consolidação epidemiológica ${ }^{3}$.

Os principais desafios da doença de Chagas no Brasil a serem enfrentados, nos próximos anos, são: os riscos de reemergência da transmissão pelo $T$. infestans; a adaptação $0^{1}$ de outras espécies de triatomíneos, secundários, ao domićlio; a desativação dos programas de controle e de vigilância vetorial em muitos municípios; a necessidade de atenção médica e social à grande massa de chagásicos crônicos necessitando de tratamento; 0 estudo e a prevenção de mecanismos alternativos de transmissão, como por via oral; e o controle do ufanismo de pesquisadores, sanitaristas e executivos de agências nacionais e internacionais que consideram a doença de Chagas com os dias contados, o que não é verdade e possibilita redução ainda maior nos recursos e prioridades destinados ao controle da doença ${ }^{3}$.

A possibilidade de interpretações errôneas acerca do significado correto da certificação conferida ao Brasil, pela Organização Pan-americana da Saúde, nos leva à discussão de 0 quanto tais informações podem ser responsáveis pela desmobilização de toda a sociedade para um problema que está longe de ser controlado, com significativo prejuízo para as ações de controle, que buscam a participação ativa da populaçãa $0^{13}$.

Faz-se necessário discutir, com maior atenção e profundidade, o controle da doença de Chagas no Brasil, buscando sempre 0 envolvimento de toda a sociedade, em especial da comunidade científica, pois esta desempenha um importante papel na disseminação, inclusive educacional, de informações fidedignas acerca da verdadeira situação de saúde relativa à doença de Chagas no país.

\section{Israel de Lucena Martins Ferreira ${ }^{1}$ e Tiago Pessoa Tabosa e Silva ${ }^{1}$}

\section{REFERÊNCIAS BIBLIOGRÁFICAS}

1. Borges EC, Pires HHR, Barbosa SE, Nunes CMS, Pereira MH, Romanha AJ, Diotaiuti L. Genetic variability in Brazilian triatomines and the risk of domiciliation. Memórias do Instituto Oswaldo Cruz 94( supl 1):371-373, 1999 .

2. Dias JCP. Vigilância epidemiológica em doença de Chagas. Cadernos de Saúde Pública 16( supl 2) :43-59, 2000.

3. Dias JCP. 0 controle da doença de Chagas no Brasil. In: Silveira AC ( org) 0 Controle da Doença de Chagas nos Países do Cone Sul da América: História de uma iniciativa internacional 1991-2001. Organização PanAmericana da Saúde, Brasília, p.145-250, 2002.

4. Dias JCP, Schofield CJ. Controle da transmissão transfusional da doença de Chagas na Iniciativa do Cone Sul. Revista da Sociedade Brasileira de Medicina Tropical 31:373-383, 1998.

5. Dias JCP, Silveira AC, Schofield CJ. The impact of Chagas disease control in Latin America: a review. Memórias do Instituto Oswaldo Cruz 97:603-612, 2002.

6. Ministério da Saúde. Notícias. http://www.saude.gov.br. Acessado em 10/ Jun/2006.

7. Moncayo A. Chagas disease: current epidemiological trends after the interruption of vectorial and transfusional transmission in the Southern Cone countries. Memórias do Instituto Oswaldo Cruz 98:577-591, 2003.

8. Organização Mundial de Saúde. Chagas disease. Elimination of transmission, Uruguay. Weekly epidemiological record 59:38-40, 1994. 
9. Organização Mundial de Saúde. Chagas disease. Interruption of transmission, Chile. Weekly Epidemiological Record 70:13-16, 1995.

10. Organização Pan-Americana da Saúde. Documento OPS.PNSP/92-18 sobre a Iniciativa do Cone Sul. Washington DC, 1992.

11. Prata A. Evolution of the clinical and epidemiological knowledge about Chagas disease 90 years after its discovery. Memórias do Instituto Oswaldo Cruz 94( supl 1) :81-88, 1999.

12. Prata A. Clinical and epidemiological aspects of Chagas disease. Lancet Infectious Diseases 1:92-100, 2000.

13. Ramos Jr AN, Alberto N, Carvalho DM. Os diferentes significados da certificação conferida ao Brasil como estando livre da doença de Chagas. Cadernos de Saúde Pública 17:1403-1412, 2001.
14. Silveira AC. Situação do controle da transmissão vetorial da doença de Chagas nas Américas. Cadernos de Saúde Pública 16(supl 2):35-42, 2000.

15. Silveira AC. 0 Controle da Doença de Chagas nos Países do Cone Sul da América: História de uma iniciativa internacional 1991-2001. In: Silveira AC (org) 0 Controle da Doença de Chagas nos Países do Cone Sul da América: História de uma iniciativa internacional 1991-2001. Organização Pan-Americana da Saúde, Brasília, p.15-43, 2002.

16. Silveira AC, Vinhaes MC. Elimination of vector-borne transmission of Chagas disease. Memórias do Instituto Oswaldo Cruz 94( supl 1):405-411, 1999.

17. Vinhaes MC, Dias JCP. Doença de Chagas no Brasil. Cadernos de Saúde Pública 16(supl 2) :7-12, 2000. 